\title{
Is some sexual offending underpinned by obsessionality?
}

Dr Vincent Egan (vincent.egan@ nottingham.ac.uk)

Associate professor in Forensic Psychology Practice

Centre for Family and Forensic Psychology

University of Nottingham

YANG Fujia Building

Jubilee Campus

Wollaton Road

Nottingham

NG8 1BB, UK

Tel: (44) 01158466627

Email: vincent.egan@ nottingham.ac.uk

Internet:

http://www.nottingham.ac.uk/medicine/about/psychiatryandappliedpsychology/people/vincen t.egan

Chapter for 'Working with Sex Offenders' edited by D.T. Wilcox, M.L. Donathy, R. Gray and A. Bain (Routledge, UK, 2016 in press) 


\subsection{INTRODUCTION}

Sexual offending may reflect a failure of morality, bad habits, poor inhibitions, behavioural or psychiatric conditions, or a combination of all of these factors and more. Certainty regarding the mechanisms involved in complex behaviours for individuals is often an indication that the observer lacks a full grasp of the nature of the problem in question.

Nevertheless, some findings with offenders seem relatively unambiguous. For example, a history of inattention, impulsivity, and hyperactivity in children underlies much subsequent offending in adults (Babinski, Hartsough, \& Lambert, 1999). Structured forensic rehabilitation programmes seeking to intervene with offenders in private and public criminal justice systems recognise impulsivity and thoughtlessness are common personal difficulties in offenders, so treatment programmes are very much based on risk-need-responsivity principles to make persons more thoughtful. Travers, Mann, and Hollin (2014) found that attending "enhanced thinking skills" (ETS) programmes was associated with significantly reduced reoffending by $13 \%$ for sexual offenders, $17 \%$ for violent offenders, and $10-12 \%$ for other non-acquisitive offenders. Sexual offenders are particularly mindful of the anticlimactic nature of their efforts, and, at least in discussion with practitioners, often express that any brief sexual pleasure derived from their crime was not worth the problems it caused.

Practitioners also see the other side of successful graduates from offender treatment programmes: individuals who continue to make bad choices despite successfully leaving prison or Probation-based evidence-based, structured cognitive-behavioural programmes of the kind Travers et al describe. This chapter argues that some difficulties working with sexual offenders follow from treating them as if they are a homogenous group, rather than recognising systematic individual differences in personality and individual psychopathology that shape the trajectory of subsequent criminal careers and putative rehabilitation (Harkins \& Beech, 2007). This chapter will present a brief review of the overlapping concepts of obsessionality, sexual addiction, hypersexuality, and sexual preoccupation, exploring how they relate to sexual offending and their care. A case example illustrates some of these points. It is proposed that recognition of these constructs may improve the care and management of some of the more chronic offenders. 
1.1 Obsessive compulsive disorder.

Obsessive-compulsive disorder (OCD) is a repetitive, unpleasant and intrusive condition which is anxiety-provoking and distressing. Persons experience obsessions (intrusive, recurring thoughts) which may evoke particular compulsions (fixed behavioural responses). DSM-IV (American Psychiatric Association, 2000) describes obsessions in terms of four cardinal features; recurrent and persistent thoughts, impulses and images that are experienced as intrusive and inappropriate or guilt-provoking, and cause clear anxiety and distress; that the content of these cognitions is more than excessively worrying about real-life problems; that efforts are made to ignore or suppress such thoughts, or by neutralisation via other thoughts or behaviours; and lastly, that the patient recognises that their obsessions are the product of their own mind. Compulsions are repetitive behaviours or mental acts the person feels driven to initiate in response to the obsession; such behaviours or thoughts are intended to prevent or reduce distress evoked by not carrying out these acts (known clinically as 'thought-action fusion') (DSM-IV, 2000). The emotions elicited by OCD are incompatible with how the individual sees themselves, and so 'ego-dystonic', rather than congruent with the person's identity ('ego-syntonic'). Revisions to the DSM-V now allows an individual to be purely obsessional or compulsive, as well as a combination of the two (DSM-V, 2013). OCD is a specific condition related to other tic and anxiety-related conditions, and different to obsessive-compulsive personality disorder, which involves constriction of identity and emotion due to the individual's perfectionism and rigidity of outlook, problems achieving goals and tasks due to their rigidity, negative feelings, and perseveration (Diedrich \& Voderholzer, 2015).

Some persons on the OCD spectrum have aspects of the diagnosis, but have other features that are atypical to the disorder. These include somatic habits such as nail-biting, hair-pulling, and skin-picking, and behavioural problems such as compulsive hoarding, all of which may harm an individual or cause them mental distress, and none of which respond well to standard OCD treatments (e.g., Bloch et al, 2014). Dimensional measures of OCD symptoms sample the wide range of clinical and subclinical behaviours associated with the condition. The Yale-Brown Obsessive-Compulsive Scale (YBOCS) is the most commonly used assessment instrument for OCD, and examines the presence of many associated symptoms, along with their severity (Goodman et al, 1989a, 1989b). The YBOCS reduces to four key dimensions; hoarding; symmetry (symmetry obsessions and repeating, ordering, and counting compulsions); cleaning and contamination; and forbidden thoughts (aggression, 
sexual, religious, and somatic obsessions, and checking compulsions) (Bloch, LanderosWeisenberger, Rosario, Pittenge, \& Leckman, 2008). Sexuality clearly lies in the "forbidden thoughts" area of the conceptual space defined by the instrument.

Two final issues to consider when examining whether an OCD model is helpful for understanding sexual offenders are whether a behaviour is impulsive or compulsive, and whether the client perceives their behaviour to be part of their identity or not. The diversity and complexity of the behaviour in question probably allows for both to be true, depending on the conditions and the individual involved. Many criminal offences are underpinned by impulsivity, and sexual offences are no exception (Gannon, Terriere, \& Leader, 2012). The lack of, or over-riding of, inhibition contributes to the development of many sexual offences, and persons who commit such offences may have concurrent behavioural expressions of impulsivity such as substance misuse, problematic consumption generally, self-harming and parasuicide (Moeller et al, 2001). Behaviours congruent with a person's identity tend to be pleasurable and positively reinforced, whereas behaviours incompatible with how a person sees themselves are negatively reinforced through the reduction of anxiety. Depending on whether one is detected or not, and an individual's evolving perspective on their sexual offending, both may occur regarding the same behaviour at different points in their offence career trajectory, thus justifying individual formulations when conducting casework.

\subsection{Operationalising the fixations of sexual offenders.}

There are a wide variety of sexual behaviours, most of which are legal and do not raise clinical or criminal interest until a given boundary is breached, or the predilection causes a difficulty. For example, in practice, many fetish items can be purchased legally, so do not draw attention unless the item is stolen, or used inappropriately. Moreover, it is only if the material is violent, or involves children or animals, that pornography is illegal in the UK or many other countries. It is therefore often possible to keep reinforcing a deviant urge without breaking a law, exemplifying the "apparently irrelevant decisions" and normalisation that underlies many offence histories. The desire to breach a boundary may lead some offenders to engage in repetitive offence-chains. Paraphilia in a risky individual can lead to offenceescalation of increasing seriousness (Milton, Duggan, Latham, Egan, \& Tantam, 2002; Brankley, Goodwill, \& Reale, 2014). At the same time, an offender who admits to their indictment may be charged with a lesser crime than the behaviour suggests, enabling serious sexual offenders to sometimes pass through the system with a lesser conviction and less 
concern than their offence actually warrants. A forensic practitioner who evaluates the risk of an individual based on the legal categorisation of their offence rather than a formulation and behavioural analysis regarding the individual themselves misses many aspects of the offence that may be relevant for assessing future harm. The amount of risk, effort, and energy expended in pursuing a given sexual preference is particularly indicative of how salient the preference is to the individual.

\subsection{Sexual Compulsivity.}

Many people have an inordinate pre-occupation and fascination for particular topics. With the onset of "Web 2.0" (in which user-generated digital content is produced and shared in a web-friendly browser), such systematising urges can now be applied to any interest for the benefit of anyone who uses the Internet. This follows for legal sexual preferences, but also for the illegal, for example, persons who download indecent images of children (IIOC). McManus and Almond (2014) examined UK trends underlying IIOC and sexual offences against children between 2005/2006 and 2012/2013, confirming the view that IIOC offences are increasing.

A variety of sexual behaviours show a compulsive/ addictive/ binge-indulgence pattern: these include some men and women seeking multiple hetero- or homosexual partners, and chronic masturbation, none of which is illegal. Sexual compulsivity is seen in persons who engage in recreational sex, and occurs across the range of sexual communities. This can lead to persons engaging in unsafe sex, and, whilst sexually preoccupied, may place such persons at risk of robbery, assault, rape, and even murder. Compulsive sexuality is associated with a variety of general clinical problems. For example, Odlaug et al (2014) found persons with compulsive sexual behaviour also reported more depressive and anxiety symptoms, higher levels of stress, poorer self-esteem, and higher rates of social anxiety disorder, attention-deficit/hyperactivity disorder, compulsive buying, pathological gambling, and kleptomania. These concurrent disorders are in the neurotic/ impulse-control domains.

One problem with research in the field examining compulsivity is the wide variety of terms to describe the phenomena: there are several thousand published papers on the topic, which refer variously to 'sexual addiction' 'sexual compulsivity' 'sexual impulsivity' 'sexual obsessive-compulsive disorder' 'excessive sexual desire disorder', and many permutations of these terms. All refer to sexual preoccupation (an individual who has an abnormally intense interest in sex that dominates their psychological functioning, with sex taking a many- 
formed, self-defining role and also as self-medication for low mood). Despite their greater sexual activity, the sexually preoccupied may continue to be sexually dissatisfied (Långström \& Hanson, 2006); this dissatisfaction is akin to the dissatisfaction of a drug addict who “chases their high". Sexual preoccupation significantly predicts sexual, violent, and general recidivism (Mann, Hanson, \& Thornton, 2010; Hanson \& Morton-Bourgon, 2004).

Insert table 1 here

Kafka's proposed DSM diagnosis of hypersexuality (table 1; 2003) informs the sexual interests/ preoccupation subscale of the Structured Assessment of Risk and Need-Treatment Needs Analysis (SARN-TNA, Thornton, 2002), one of the several risk assessment instruments used to assess sexual offenders by persons in the social and Probationary services. Tully, Browne and Craig (2015) found the sexual interests/ preoccupation subscale of the instrument most effective for predicting future risk of reconviction for a sexual offence, with the SARN's other subscales (offence-supportive attitudes, troubled relationships, poor self-management) showing no significant predictive effects on reconviction and risk outcomes. A raised sexual preoccupation subscale meant an individual was five times more likely to be reconvicted, whereas the next strongest effect was for offence supportive attitudes, and not statistically significant. Understanding what sexual preoccupation is therefore likely to be a more useful in terms of assessment and risk management than any other aspect of information derived from the SARN.

\subsection{Who downloads indecent pictures of children from the Internet?}

Downloading IIOC is a criminal offence. Despite threat of custody, and the shame of being identified as a paedophile to the community around you - let alone to your family and friends, the threat from vigilantes, and internet harassment - IIOC seems an increasingly common crime. This is partly because computer software tasked with identifying persons accessing particular websites, downloading particular images, or finding hidden pictures on a harddrive is now widely used by criminal justice investigators, making the detection and prosecution of IIOC downloaders much more straightforward. A large study of 422 Internetbased sex offenders by Henry, Mandeville-Norden, Hayes, and Egan (2010) found IIOC downloaders reduce to 'normal', 'inadequate', and 'deviant' groups. 'Inadequate' offenders 
were defined by social and emotional difficulties, but were not high on pro-offending measures. Deviant persons had very poor victim empathy but were more socially effective. The emotional inadequacy of the participant correlated more with their impulsivity than their deviancy; these results were not due to social desirability.

The number of persons who have been convicted for downloading IIOC leads to a question commonly raised by Probation workers: will the individual move from committing remote, non-contact ("hands-off") to active, contact ("hands-on") sexual offences? Babchishin, Hanson, and VanZuylen (2015) conducted an analysis of over 5000 sexual offenders, comparing persons convicted for possession of child pornography, a contact sexual offence, and those who committed both kinds of offence. The crossover from remote to active offending occurred in those persons who expressed a sexual interest in children, had practical access to victims, a significant previous criminal history, and a lack of internal controls to inhibit acting on sexually deviant interests. These results suggest individuals who download IIOCs are different from hands-on offenders. Aslan and Edelmann (2014) conducted a similar study in the UK, finding IIOC offenders more likely to be white, young, single or never married, better educated, in stable employment, and with fewer previous convictions for any offence. Such a profile suggests that uncomplicated IIOC downloaders are adequately managed with non-custodial sentences, and recent UK sentencing guidelines for such offences reflect this view (Sentencing Guidelines Council, 2014).

\subsection{The language of Internet grooming.}

More serious sexual offenders seek hands-on activity, and can be recklessness and compulsivity in their search, despite the high-risk nature of the activity. Egan, Hoskinson and Shewan (2011) qualitatively examined the language used by men soliciting admittedlyunderage girls in chatrooms. This data was based on a discourses (transcripts used by US courts to convict the person) posted by the "Perverted Justice" website regarding 16 persons caught as a result of their efforts. There were eight recurrent themes in the language used by the men: implicit/explicit content', on-line solicitation', fixated discourse'(i.e., preoccupied language), use of colloquialisms', conscience', acknowledgement of illegal/immoral behaviour', minimising risk of detection', and preparing to meet offline'. These observations regarding fixated discourse have been replicated in more quantitative data sets (Bogdanova, Rosso, \& Solorio, 2014). That persons can be so blithe about engaging in illegal activity 
suggests an the urge being addressed sufficiently compelling as to inhibit the considered rational consequences of a sexual offence.

\subsection{OCD and sexual offending.}

If more serious sexual offenders are more obsessional, they will find it harder to break their problematic behaviours. However, those high in obsessionality are often withdrawn and emotionally unstable, raising the possibility that any obsessionality in sexual offenders is due to their underlying personality. Egan, Kavanagh, and Blair (2005) examined if SOAP relates to personality in child molesters in a large, non-institutionalised sample, comparing child molesters to a control samples of mentally disordered offenders on the personality assessment. They examined whether the association between obsessionality and sexual offending reduced when one took their emotional problems into account. The study comprised 200 persons referred to the Leicestershire and Derbyshire Probation Service after convictions for sexual offences against children. All participants completed the Sex Offenders Assessment Package, the NEO-FFI measure of personality, and the Maudsley Obsessive-Compulsive Inventory. Although more sexual deviance was associated with greater obsessionality, the relationship remained when the effect of obsessionality (normally related to emotional instability) was controlled-for. This suggests that any obsessional aspect of a sexual offender cannot be attributed simply to emotional instability alone.

\subsection{How general is sexual obsessionality?}

Work with offenders leads one to repeatedly observe persons who have several chemical or behavioural compulsions or addictions simultaneously. The underlying neural mechanisms and chemistry for these conditions seems general. The latest behavioural addiction is uncontrolled use of the Internet and social media, which is now also the main medium for pornography. Pornography use leads to criminal antisocial behaviour in persons with preexisting anti-social personality (Ferguson \& Harley, 2009), and may cause problems in relationships for non-offenders. Egan and Parmar (2012) examined whether on-line pornography use more common in compulsive persons, and if individual differences in personality and psychopathology predicting pornography consumption. They tested if this reflected a specific or more general addictive/compulsive process, measuring personality, obsessionality, computer and sexual addiction in 226 male participants who completed an anonymous online questionnaire involving five commonly used scales; the NEO-Five Factor Inventory-Revised (NEO-FFI-R); the Maudsley Obsessive-Compulsive Inventory (MOCI); 
the Internet Addiction Test (IAT); the Sexual Addiction Screening Test (SAST); and the Cyber-Pornography Use Inventory (CPUI). A generalised addiction model explained the relationships between these measures to the same degree as a model which was much more complicated. The general addiction model is predicted by the same personality constructs as those associated with clinical problems such as negative urgency, behavioural dyscontrol, and compulsive checking. This study involved a young sample, not an offender cohort, so extrapolating these results to sexual offenders requires replication, but the results make good theoretical sense for the behaviours involved.

\subsection{Treatment implications.}

Interventions with sexual offenders involve the client becoming aware of their own risk, potential triggers to their reoffending, and the pathways that may lead to such reoffending ("offence chains"). Ideally, an offender will "intervene at the antecedent" and avoid a future offence in the first place. This means they need to monitor their own thoughts and behaviour, and the sexualised content this will sometimes involve involve. This may lead to panicked self-monitoring classically known as the 'White Bears' problem; the more one tries to not think of a white bear, the more one can think of little else (Wegner, 1989). A sexual offender may think that their spontaneous sexual thought is an immediate risk, as the taboo stimulus leads to spontaneous recovery of sexual thoughts, so their efforts to suppress the thought have failed, and they will therefore slip back into full offending. An offender may experience shame, guilt, and form an excessive preoccupation with trying to not recall that which they do not wish to think about - but because of the "white bears problem", becomes unable to switch off from such thoughts. Shingler (2009) observes that active thought suppression (trying to force oneself to not think about something) is an unhelpful strategy, and it is better to see a thought as transient, and unless acted on, quickly replaced by another; formal associational techniques may assist a client in moving away from a troubling thought to a thought with more anodyne content, enabling them to become more in control of themselves.

Offenders with intrusive sexual thoughts can be helped in a variety of ways, all of which may involve addressing notions of sexual preoccupation/ sexual addiction/ sexual compulsivity, or whatsoever term is favoured to describe the phenomena under discussion. These include relapse prevention work, arousal reconditioning, coping skills training, and learning to break dissociative states which can otherwise lead a person to fall into a predatory mind-set where they 'cruise' for sex or potential victims of an offence. Life goes on, and 
sexual offenders cannot practicably live in a world free of risky cues. These may be better managed by exposure and ritual prevention, breaking down behaviour feedback loops which otherwise reinforce the behaviour.

\section{9: Case example.}

A “children's entertainer" was referred for assessment due to their having been arrested for attempting to persuade children to touch him indecently. He had served two previous custodial sentences for similar offences, and had completed SOTP during one of these. Assessment of the client indicated that they compulsively used food, alcohol, and cigarettes to an unhealthy degree. The client had never formed satisfactory sexual relations with another adult involving an interpersonal dimension, and would visit male lavatories known to be places where men had sex with each other, and engage in anonymous sex. When asked about the index offence, he observed that the 11-year old boys had been "flirting" with him, and it was therefore unsurprising that he had become sexually aroused when speaking to them at his toy stall at a street market. He said he never felt freer than when in the company of boys of about 11 or 12 . It was for this reason that he asked them to punch him in the genitals, as it was only in this way that the excitement would pass and be marked instead by pain, discouraging him from pursuing his offence. The boys instead told their fathers, and the client was arrested. The client was very sexually preoccupied, and continued to engage in aspects of his life that cued him into his paedophilic interests, such as acting as a children's entertainer and running a toy stall at a market, both of which drew children to him.

This case example exemplifies several issues raised above; a failure to change a lifestyle so that risky cues are less probable; prior sexual offending, indicative that the difficulty is of long-standing; emotional dysregulation and loneliness; the desire to take a risk even when it is likely to prove disastrous; general over-consumption without judicious regulation to maintain health; sexual functioning incompatible with the emotional and interpersonal dimension that may make it more satisfying; and an inadequate (although doubtless thought-stopping) solution to uncouple the deviant thoughts and response he had. The client was given another lengthy sentence, and placed on the enhanced SOTP programme. 


\subsection{Conclusions.}

The links between some sex offending and OCD phenomenology is bound to be inexact as sexual offending is diverse. However, the implementation of intervention studies using approaches described above may be effective in addressing sexual preoccupation in offenders. The criterion for an effective outcome remains moot: meaningful behavioural tests of sexual preoccupation would be ideal, but need to show the necessary validity and reliability to be acceptable to the authorities overseeing practice. There has not been a lot of research examining whether some sexual offenders have greater tic disorders, or other 'addictions' as would support the proposed model in this chapter. Prison work with offenders does not engage in individual clinical work. Foddy (2011) argues that terms such as "addiction" can be unhelpful, given that one might be simply observing a craving for something an individual desires. However, the term does convey the compulsion that may underlie the behaviour of the offender. It is clear there is network of interrelationships between sexual interest, and related synonyms of more or less clinical rigour, and though practitioners may try to avoid loaded and confusing terms like "addiction“", or "compulsivity“ being applied to disorders of sexual appetite, it is questionable whether these are worse than seeing such an appetite as greed, sensuality, moral failing, or an over-medicalised bad habit. Whatever the language involved, the problem is one of behavioural dyscontrol, problems stopping an action, problematic consequences, and the patient attempting to control the problematic thought by an even more problematic behaviour. 
1.10 References

American Psychiatric Association. (2000). Diagnostic and statistical manual of mental disorders (4th ed., text rev.). Washington, DC, USA.

American Psychiatric Association (2013). Diagnostic and statistical manual of mental disorders : DSM-5 (5th ed.). Washington DC, USA: American Psychiatric Publishing.

Aslan, D., \& Edelmann, R. (2014). Demographic and offence characteristics: a comparison of sex offenders convicted of possessing indecent images of children, committing contact sex offences or both offences. The Journal of Forensic Psychiatry \& Psychology, $25(2), 121-134$.

Babinski, L. M., Hartsough, C. S., \& Lambert, N. M. (1999). Childhood conduct problems, hyperactivity-impulsivity, and inattention as predictors of adult criminal activity. Journal of Child Psychology and Psychiatry, 40(03), 347-355.

Babchishin, K. M., Hanson, R. K., \& VanZuylen, H. (2015). Online child pornography offenders are different: A meta-analysis of the characteristics of online and offline sex offenders against children. Archives of sexual behavior, 44(1), 45-66.

Bloch, M. H., Bartley, C. A., Zipperer, L., Jakubovski, E., Landeros-Weisenberger, A., Pittenger, C., \& Leckman, J. F. (2014). Meta-analysis: hoarding symptoms associated with poor treatment outcome in obsessive-compulsive disorder. Molecular psychiatry, 19(9): $1025-1030$.

Bloch, M.H., Landeros-Weisenberger, A, Rosario, M.C., Pittenge, C., Leckman, J.F. (2008). Meta-analysis of the symptom structure of obsessive-compulsive disorder. American Journal of Psychiatry, 165:1532-1542.

Bogdanova, D., Rosso, P;, \& Solorio, T. (2014). Exploring high-level features for detecting cyberpedophilia. Computer Speech and Language. 28(1):108-120

Brankley, A. E., Goodwill, A. M., \& Reale, K. S. (2014), Escalation from fetish burglaries to sexual violence: A retrospective case study of former Col., D. Russell Williams. Journal of Investigative Psychology and Offender Profiling, (11), 115-135. doi: 10.1002/jip.1406 
Diedrich, A., \& Voderholzer, U. (2015). Obsessive-compulsive personality disorder: a current review. Current psychiatry reports, 17(2), 1-10.

Egan, V., Kavanagh, B., \& Blair, M. (2005). Sexual offenders, personality and obsessionality. Sexual Abuse, 17, 223 - 240. DOI: 10.1007/s11194-005-5053-4.

Egan, V., Hoskinson, J., Shewan, D. (2011). Perverted justice: content analysis of the language used by offenders detected attempting to solicit children for sex. In R.M. Clarke (Ed.) Antisocial Behavior: Causes, Correlations and Treatments, Nova Publishers, Happusage, New York 119 - 134. ISBN 978-1-61122-890-8.

Egan, V., \& Parmar, R. (2013). Dirty habits? On-line pornography use as a function of personality, obsessionality, and compulsivity. Journal of Sexual and Marital Therapy, 39, (5), 394-409. DOI:10.1080/0092623X.2012.710182.

Ferguson, C.J., \& Hartley, R.D. (2009). The pleasure is momentary...the expense damnable? The influence of pornography on rape and sexual assault. Aggression and Violent Behavior, 14, 323-329. DOI:10.1016/j.avb.2009.04.008.

Foddy, B. (2011). Addiction and its sciences-philosophy. Addiction, 106, 25-31.

Gannon, T., Terriere, R., \& Leader, T. (2012). Ward and Siegert's Pathways Model of child sexual offending: a cluster analysis evaluation. Psychology, Crime \& Law, 18(2), 129153.

Goodman, W.K., Price, L.H., Rasmussen, S.A., Mazure, C., Fleischmann, R.L., Hill, C.L., Heninger, G.R., \& Charney, D.S. (1989a) The Yale-Brown Obsessive Compulsive Scale, I: development, use, and reliability. Archives of General Psychiatry, 46, 1006-1011.

Goodman, W.K., Price, L.H., Rasmussen, S.A., Mazure, C., Delgado. P., Heninger, G.R., Charney, D.S. (1989b). The Yale-Brown Obsessive Compulsive Scale, II: validity. Archives of General Psychiatry, 46, 1012-1016.

Harkins, L., \& Beech, A. R. (2007). A review of the factors that can influence the effectiveness of sexual offender treatment: Risk, need, responsivity, and process issues. Aggression and Violent Behavior, 12(6), 615-627. 
Hanson, R. K., \& Morton-Bourgon, K. E. (2004). Predictors of sexual recidivism: An updated meta-analysis (Corrections User Report No. 2004-02). Ottawa, Ontario, Canada: Public Safety Canada.

Henry, O., Mandeville-Norden, R., Hayes, E., \& Egan, V. (2010). Do Internet sexual offenders reduce to normal, inadequate and deviant groups? Journal of Sexual Aggression, 16, 33-46. doi.org/10.1080/13552600903454132

Kafka, M. P. (1997). Hypersexual desire in males: An operational definition and clinical implications for males with paraphilias and paraphilia-related disorders. Archives of sexual behavior, 26(5), 505-526.

Kafka, M. P. (2003). Sex offending and sexual appetite: The clinical and theoretical relevance of hypersexual desire. International Journal of Offender Therapy and Comparative Criminology, 47(4), 439-451.

Långström, N., \& Hanson, R. K. (2006). High rates of sexual behavior in the general population: Correlates and predictors. Archives of Sexual Behavior, 35(1), 37-52.

Mann, R. E., Hanson, R. K., \& Thornton, D. (2010). Assessing risk for sexual recidivism: Some proposals on the nature of psychologically meaningful risk factors. Sexual Abuse: A Journal of Research and Treatment, 22(2), 191-217.

McManus, M. A., \& Almond, L. (2014). Trends of indecent images of children and child sexual offences between 2005/2006 and 2012/2013 within the United Kingdom. Journal of sexual aggression, 20(2), 142-155.

Milton, J., Duggan, C., Latham, A., Egan, V., \& Tantam, D. (2002). Case history of co-morbid Asperger's syndrome and paraphilic behaviour. Medicine, science and the law, $42(3), 237-244$.

Moeller, F. G., Barratt, E. S., Dougherty, D. M., Schmitz, J. M., \& Swann, A. C. (2001). Psychiatric aspects of impulsivity. American journal of psychiatry, 158 (11), 17831793.

Odlaug, B. L., Lust, K., Schreiber, L. R., Christenson, G., Derbyshire, K., Harvanko, A., Golden, D, \& Grant, J. E. (2013). Compulsive sexual behavior in young adults. Annals of Clinical Psychiatry, 25, 193-200. 
Salkovskis, P. M., Wroe, A. L., Gledhill, A., Morrison, N., Forrester, E., Richards, C., ... \& Thorpe, S. (2000). Responsibility attitudes and interpretations are characteristic of obsessive compulsive disorder. Behaviour Research and Therapy, 38, 347-372.

Sentencing Guidelines Council (2014). Magistrates' Court Sentencing Guidelines. Downloaded from: http://www.sentencingcouncil.org.uk/wp-content/uploads/MCSG_web__October_2014.pdf

Shingler, J. (2009). Managing intrusive risky thoughts: What works? Journal of Sexual Aggression, 15(1), 39-53.

Travers, R., Mann, R.E., \& Hollin, C.R. (2014). Who benefits from cognitive skills programs?: Differential impact by risk and offence type. Criminal Justice and Behavior, (41): 1103-1129, doi:10.1177/0093854814543826

Tully, R.J., Browne, K.D., \& Craig, L.A. (2015). An examination of the predictive validity of the Structured Assessment of Risk and Need Treatment Needs Analysis (SARNTNA) in England and Wales. Criminal Justice and Behavior, 42(5), 509-528.

Wegner, D. M. (1989). White bears and other unwanted thoughts: Suppression, obsession, and the psychology of mental control. London, UK: Penguin Press 
Table 1: Kafka's proposed criteria for hypersexuality

A. Over a period of at least six months, recurrent and intense sexual fantasies, sexual urges, and sexual behaviour in association with four or more of the following five non-paraphilic criteria:

1. Excessive time consumed by sexual fantasies and urges, and by planning for and engaging in sexual behaviour.

2. Repetitively engaging in these sexual fantasies, urges, and behaviour in response to dysphoric mood (e.g., anxiety, depression, boredom, irritability)

3. Repetitively engaging in sexual fantasies, urges, and behavior in response to stressful life events.

- Affect regulation/ tension reduction

4. Repetitive but unsuccessful efforts to control or significantly reduce these sexual fantasies, urges, and behaviour.

Abstinence violation, relapse prevention, reduce FID, engineer coping

5. Repetitively engaging in sexual behaviour while disregarding the risk for physical or emotional harm to self or others.

Behavioural over-ride

Exclude bipolar (manic) illness, Parkinsonian or MS treatment, dementia. 